\title{
Interventions for people with autism: recent advances
}

\author{
Patricia Howlin
}

Autism is a pervasive and life-long disorder that is characterised by profound deficits in communication and social understanding, together with ritualistic and obsessional behaviours and a general resistance to change. Although usually associated with additional cognitive impairments (approximately $50 \%$ of those affected have an IQ below 50 ) the condition can occur in individuals of all levels of ability, and around $20 \%$ of cases have an IQ within the normal range. Estimates of prevalence vary from 3.3 to 16.0 per 10000 and rates may be even higher if children within the autistic wider spectrum are included (Wing, 1993, 1996). Understanding of causation is still limited, although genetic factors are now known to play a major role (Lord \& Rutter, 1994).

The parents of children with autism are faced with many different problems, most of which result from the social, linguistic or obsessional difficulties that are fundamental to the disorder. They also face bewildering and often conflicting claims about the merits of different interventions. Various approaches to treatment are described below, and their relative merits and limitations discussed.

\section{Treatment approaches}

There are numerous treatments that, over the years, have been claimed to have a dramatic impact on autism, or even to cure the condition completely. These include 'holding therapy' (Welch, 1988; Richer \& Zappella, 1989); scotopic sensitivity training, which involves the wearing of special spectacles (Irlen,1995); auditory integration, which focuses on desensitisation to sounds of particular frequencies (Stehli, 1992); and various drug and vitamin treatments (Rimland, 1994a,b). Unfortunately, on the whole, the more extravagant the promises the more limited are the experimental data on which they are based.

One such example is 'facilitated communication', which requires a 'facilitator' to support the client's hand, wrist or arm, while he or she uses a computer or letter board to communicate. Through these means, individuals with autism are said to be able to demonstrate superior intellectual powers, to take part in political or philosophical debate, and even produce poetry (Biklen, 1993). However, controlled investigations have consistently indicated that responses are almost invariably under the control of the facilitator, not the client (Green, 1994).

Although it is well established that structured and behavioural approaches to intervention can have a significant impact on the behaviour of children with autism, even here caution is required in interpreting some of the claims made. 'Daily life therapy', with its focus on highly structured, intensely physical programmes as practised in the Higashi schools in America and Japan, is said to produce impressive outcomes in children with autism (see Gould et al, 1991). The 'Options' method of Kaufman (1981), which relies on teachers participating in the child's ritualistic and obsessional behaviours in order to foster social contacts, also claims 'miraculous' results. Recently, too, Lovaas and colleagues in California (McEachin et al, 1993) have claimed that over $40 \%$ of cases with autism can be cured if children are exposed to very intensive behavioural training and education from an early age. Recovery from autism has also been cited by other practitioners using this approach (Perry et al, 1995). However, possible

Dr Howlin is Tutor in the Psychology of Learning Disability for South Thames Regional Health Authority, and Senior Lecturer in Psychology at St George's Hospital Medical School. She is a Consultant Chartered Clinical Psychologist and a Fellow of the British Psychological Society. She has been working with people with autism and their families for many years. 
biases in subject selection, problems of research design and, most importantly, in the definitions of normality used, make the interpretation of results very difficult. Thus, children are claimed to have recovered if they are of normal IQ and can be assimilated into mainstream education. However, as around $20 \%$ of all autistic children are of normal intellectual ability and many do attend normal schools, despite showing clear autistic features, such a definition of cure is hardly tenable. From a practical point of view, too, there are many problems. The programme involves 40 hours of one-to-one intervention a week for at least two years and, although some families may be able to cope with such demands, the cost for others (emotionally, financially and practically) is far too high. Moreover, although programmes of this kind may enhance short-term progress there are no controlled studies demonstrating lasting benefits.

From time to time it has been claimed that various drug treatments offer significant benefits, although few of these claims have been supported by adequately controlled trials. For example, fenfluramine was widely promoted throughout the 1980s (Ritvo et al, 1986), but later studies suggested that the response to treatment was very variable, and a wide range of negative side-effects has subsequently been identified. Other frequently used drugs (at least in the USA) include haloperidol, naltrexone, clomipramine, clonidine and methylphenidate but many other pharmacological approaches to treatment have also been tried. Few are without side-effects and Campbell et al (1996) warn that:

No conclusions can be made concerning the efficacy and safety of these agents because the findings are based on small sample sizes and open studies without placebo control.

For updates on the effects of other drug treatments see reviews by Coleman (1992), Campbell \& Cueva (1995) and Lewis (1996).

In short, there is no evidence that any cures for autism exist, and the fact that some individuals may be able to attend normal school, find a job or even get married, does not mean that they are

Box 1. Essential questions for intervention programmes

Why does the behaviour occur?

What does this behaviour achieve for all the individuals concerned (carers as well as children)?

What can be done to replace it? cured, nor that the treatment advocated has been responsible for their progress. Many able children do well despite totally inadequate provision, and to a great extent eventual outcome is dependent on innate cognitive, linguistic and social abilities. Nevertheless, early and appropriate intervention can have a significant impact on minimising or avoiding behavioural problems and in helping to ensure that children with this condition are able to develop their existing skills to the full (Howlin \& Rutter, 1987).

\section{Reducing behavioural problems}

The essence of any successful intervention programme is the need to recognise that apparently similar problems can have very different causes in different children, or even within the same child at different times. Difficulties such as temper tantrums, feeding and toilet problems, and destructive and aggressive behaviours, may result from a variety of sources. They may arise because of a child's inability to communicate; because they lack alternative strategies to control the people or environment around them; because of frustration, anxiety or fears; or because of disruption to rituals and routines. Before embarking on any attempts to change behaviour, therefore, there are certain crucial questions to be asked (Box 1).

Although problem behaviours in autism, as in any other condition, will be maintained or increased by the attention or reinforcement they receive, techniques such as time out, extinction, or differential reinforcement will not be discussed here. Many hundreds of papers have been written on the use of such methods (see Emerson, 1995) and there is no doubting their general effectiveness, but they are not specific to the treatment of autism. Instead, this paper will attempt to illustrate how recognition of the fundamental deficits in autism (communication, social understanding and obsessional and ritualistic tendencies) is essential for the effective management of behavioural difficulties (Table 1).

\section{Impact of communication deficits}

Although, as noted above, there are many possible causes of behavioural disturbance in autism, impairments in communication are without doubt the most significant. Around one-third of autistic individuals remain without speech, but even among those whose speech is well developed, there are persisting and pervasive impairments in the 


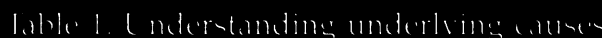

Principal diagnostic features

Impairments in communication and understanding
Principal causes of behavioural problems

$$
\begin{aligned}
& \text { Inability to communicate effectively leads to frustration and possibly aggression; } \\
& \text { unacceptable attempts to control environment; inappropriate use of speech (echolalia, } \\
& \text { verbal routines, obsessional questions etc.) } \\
& \text { Poor comprehension results in anxiety, distress; disruptive behaviours and lack of cooperation } \\
& \text { Lack of internal language affects imaginative skills and ability to play; limits the } \\
& \text { development of self-control }
\end{aligned}
$$

Impairments in social understanding

\section{Lack of social awareness in less able individuals may result in withdrawal and isolation and very disturbed/disruptive behaviours in public. Among the more able, attempts} to socialise are often inappropriate and may offend or antagonise others

Obsessional and ritualistic behaviours
Obsessional behaviour patterns can severely limit the acquisition of other more productive behaviours/skills. In more able individuals may impose major limitations on other people's activities also

Disruption of routines can result in serious distress, disruption and aggression

Dislike of change leads to very rigid and inflexible patterns of behaviour and great distress and anxiety if change is necessary communicative use of language and in understanding complex or abstract concepts. Indeed, personal accounts by individuals with autism (Grandin \& Scariano, 1986; Jolliffe et al, 1992; Williams, 1992; 1994) provide striking examples of how the inability to communicate effectively, to make sense of what others are saying or of what is going on around them, produces enormous distress and anxiety as well as leading to aggressive or disruptive behaviours, or to withdrawal into ritualistic and obsessional activities.

\section{Improving communicative competence}

In recent years, some of the most promising attempts to improve communication skills have resulted from research into behavioural problems. It has become increasingly evident that many disruptive or 'challenging' behaviours have an important communicative function for people with autism (Durand, 1990). Thus, far from being inappropriate, such behaviours may be the only way in which an individual with very limited communication skills can rapidly, effectively and predictably control his or her environment. Analysis of these problems frequently indicates that so-called 'maladaptive behaviours' may be extremely adaptive and effective if an individual is unable to express his or her needs, feelings or emotions in any other way. Thus, it may be much easier to get attention or avoid unwanted events by screaming or throwing something than by trying to explain verbally what is the matter.
If the underlying reasons for the disruptive behaviours can be established, and individuals then provided with alternative and more socially acceptable ways of indicating their needs, this can significantly reduce aggressive, self-injurious or stereotyped behaviours, while increasing communication skills. Enabling people with autism to express their needs or to escape unwanted situations by means of a simple word, phrase, sign or picture, or simply by pushing a button or switch, can have rapid and positive effects (Durand \& Carr, 1991).

Although much of the work in this area was initially conducted in highly intensive experimental settings, these procedures have since been adapted for use in more natural settings. For example, Schuler et al (1989) have developed a simple questionnaire that can be used by parents or teachers to explore how children with autism communicate their displeasure or their needs for attention, physical contact, food or toys. Once the primary function of a behaviour has been identified in this way, the individual can be provided with alternative forms of communication (signs, words, simple phrases, pictures, symbols or gestures) to obtain the same ends. Moreover, by helping carers to appreciate that such behaviours may be a function of poor communication skills, rather than being 'deliberate' acts of aggression or provocation, this approach can have a very positive effect on others' attitudes and responses. 
Increasing general communicative ability

Because many children with autism will never acquire useful speech, alternative systems of communication will often be required. Layton \& Watson (1995) provide a useful breakdown of the different skills required for using signs, pictures or written words (Table 2). On the whole, a pictorially based system makes least demands on cognitive, linguistic or memory skills, although it is essential that the pictures or photographs used reflect the individual's particular interests or needs. It also seems to be important for the autistic person to take an active role in using and handling such materials (e.g. using Velcro or stickers to place them appropriately, rather than passively watching others) in order to establish the association between the illustration and the relevant item or activity. Once this association is made, individualised sets of photographs or pictures can be used very effectively to increase both communication and understanding (Quill, 1995).

Computerised communication devices have become steadily more sophisticated in recent years, and some are now specifically adapted for use with autistic individuals. Interchangeable keyboards of increasing complexity make it possible for students to progress gradually from single-symbol boards (with, for example, a large red square or circle that will emit a sound to attract attention) to eventually the independent use of multi-symbol displays, that are personally tailored to the individual's own environment, needs or interests. Computers can also be very valuable teaching aids for more able individuals who may respond better to information on the screen than to information given verbally. However, when using computers with this group care needs to be taken to ensure that some social interaction also occurs, otherwise communication may be with the machine, and noone else!

Parents are sometimes concerned that teaching children to communicate by alternative means will reduce the chances of their ever learning to speak. However, the use of augmentative procedures may actually encourage some previously non-verbal children to use speech (Howlin, 1989). It is also important to be aware that very few children who have not acquired some useful speech by the age of 6-7 years subsequently develop good language. Thus, fostering alternative means of communication as soon as possible is likely to avoid problems in the future.

Augmentative systems can also prove extremely helpful for children who have no obvious speech problems. Almost all individuals with autism, no matter how able, have difficulties with abstract or complex language. Although they may understand the individual words spoken, they may well misinterpret or fail to understand the underlying meaning of what is said. Thus, if given a simple instruction such as, "Go and ask your mum if she wants a cup of tea", they may well do so, but unless specifically told they are unlikely to bring back any reply. For this group, check-lists of simple instructions, picture or cartoon sequences of activities to be completed, or symbols designating the tasks to be done, can all result in much more attention to detail, and far greater success in completing activities, than verbal instructions (or nagging) will ever do.

Visual instructional systems have been used successfully in educational programmes for children with autism. The TEACCH programme, developed in North Carolina, relies heavily on visual cues or 'jigs' so that, throughout the day,

Table 2. Assessment for communication strategies (from Layton \& Watson, 1995)

\begin{tabular}{|llll|}
\hline \multicolumn{4}{|c|}{ Table 2. Assessment for communication strategies (from Layton \& Watson, 1995) } \\
\hline & Signing & Pictures/pictographs & Writing \\
\hline Characteristics & & & \\
Easily shaped & Yes & Yes & Fairly \\
Portability & High & Moderate & High \\
Permanence & No & Yes & Yes \\
Speed & Moderate/low & Low & High/moderate \\
Phrases possible & Moderate & Limited & Yes \\
Iconicity & Some & Yes & No \\
Reciprocity & Limited & Limited & High \\
Skills required & & & \\
Motor skills & Yes & No & Yes \\
High cooperation & Not initially & Not initially & Not initially \\
Demands on others' & Yes & No & No \\
\multicolumn{1}{|c|}{ understanding } & & & \\
\hline
\end{tabular}


differently coloured work areas or containers are used to indicate where the child should be, what he or she should be doing, where work should begin or be placed when finished, and even where to play. This combination of a highly structured and visual programme can be very successful in improving work-related skills and reducing inappropriate behaviours (Jordan \& Powell, 1995). However, as with any treatment package, it is important that the basic components are adapted to suit the needs of the individual and his or her environment, and to plan for the gradual reduction in such cues if the child is eventually to be able to function effectively in other surroundings.

\section{Echolalic speech}

Echolalia, both immediate and delayed, is a common feature of autism. Again, although often considered inappropriate and non-communicative, as well as being highly irritating, detailed analyses indicate that much echoing serves identifiable and important communicative functions (Rydell \& Prizant, 1995). As with any other autistic behaviour, therefore, it is crucial to assess the role that the echolalia serves before attempts are made to modify this.

First, echoing is often a sign that children have not understood what has been said, and may indicate the need for other people to simplify their own speech. Second, echolalia is more likely to occur when individuals are stressed, anxious or in highly constraining situations, where repetition can play an important role in dealing with feelings of distress or anxiety. Understanding why and when echolalia is likely to occur, and acceptance of the importance of this for the individual with autism, may well help others to be more tolerant. Greater understanding may also suggest alternative strategies. For example, desensitisation to feared situations or the teaching of relaxation techniques may be a more appropriate way of dealing with the problem than 'time out' or the removal of attention. Finally, providing permanent and concrete information via pictures, written instructions or other cues may also help to clarify situations when verbal instructions alone are inadequate, again reducing the need for stereotyped speech or repetitive questioning.

\section{Coping with obsessional and ritualistic behaviours}

Research suggests that attempts totally to prevent or prohibit rituals or routines are generally counter-productive and may result in increased anxiety, disturbance and agitation. Moreover, even if attempts to stop one form of obsessional behaviour are successful, children may then proceed to develop new rituals or obsessions, which can be even more disruptive than the original ones.

A far more productive approach is gradually to modify the behaviour, so that it no longer interferes to the same extent with the lives of individuals or their families. Howlin \& Rutter (1987) suggest a variety of different approaches (discussed below) that can be used in order to minimise the disruption caused by behaviours of this kind.

\section{Adopting a 'graded change' approach}

Obsessional and ritualistic behaviours tend to grow gradually over time. In the same way, intervention programmes tend to be most successful if carried out in gradual and carefully planned stages. In order to minimise anxiety, the individual needs to know not only when the behaviour is not permitted, but also when it is allowed (Box 2).

The crucial strategy is to ensure that change is introduced one step at a time. Indeed, if possible the changes should be so small that the individual is hardly aware of them. They should certainly never be so large as to cause distress either to the child or to carers. Setting very small goals also has the advantage of optimising the chances of success, even though the ultimate goal may take weeks, or even months to attain. Table 3 lists the approaches used to reduce some ritualistic or repetitive behaviours.

\section{Addressing underlying causes}

High levels of uncertainty or anxiety frequently cause or exacerbate obsessional behaviours. Reducing stress is often the most effective way of minimising problems of this kind and by far the best way of doing this is to ensure that the individual's daily programme is as structured and as predictable as possible. When anxiety is particularly high, a combination of desensitisation and graded change procedures can be very productive. At other times,

Box 2. Setting limits on obsessional and ritualistic behaviours

Establish clear and consistent rules for:

Where the activity is permitted

Who it can be carried out with

When it can occur

How long it can go on for 
quite simple modifications to the daily routine or environment can rapidly diminish some obsessional behaviours. For example, one young girl became very disturbed shortly before every playtime, and her ritualistic behaviours intensified greatly. Allowing her not to join the other children in the playground (a nightmare scenario for many autistic children) rapidly decreased both her anxiety and rituals.

It is also important to be aware that the pressures on individuals with autism to conform to normal social rules must at times become overwhelming. As autobiographical accounts illustrate, problems are often greatest for those who are most able, and who are expected to integrate into mainstream school or college, or to cope with work, or living alone, with virtually no additional support. Having continually to disguise or suppress their autistic tendencies can be a cause of considerable distress, and allowing individuals the opportunities occasionally to escape, to sit alone and in silence, or to indulge in routine or obsessions can be crucial.

\section{Helping to predict and deal with change}

Although it is generally accepted that people with autism have difficulties in coping with change, in many cases it is the inability to cope with unpredictable change that gives rise to most problems. Verbal explanations alone are often not sufficient to clarify what is going to happen. Again, visual or written indications of the events that will take place during the forthcoming day or week, and any alterations to the regular routine, can be much more effective in helping the individual to understand when and what changes will take place.

\section{Improving the general quality of life}

Possibly the single most important element in any intervention programme for obsessional or ritualistic behaviours is the need to develop and encourage other activities. Otherwise, whatever strategies are employed, the obsessional behaviours will increasingly take over; hence, the importance of an appropriately stimulating and structured environment cannot be overstated.

\section{Making use of obsessions}

Dealing with obsessions and routines is by no means easy and successful interventions will require time, patience and often the implementation of several different strategies in tandem. The aim should not generally be to remove the obsession entirely but to

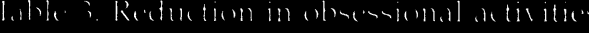

Problem Stage of intervention

\begin{tabular}{|c|c|c|}
\hline \multirow{4}{*}{$\begin{array}{l}\text { Collecting } \\
\text { coins }\end{array}$} & (1) & Reduce number of rooms where coins allowed \\
\hline & (2) & $\begin{array}{l}\text { Access to other enjoyed activities (TV, eating, getting into parents' bed) contingen } \\
\text { on coins being removed from room }\end{array}$ \\
\hline & (3) & Reduction in numbers of coins allowed in any one place \\
\hline & (4) & Coins allowed only in bedroom \\
\hline \multirow{4}{*}{$\begin{array}{l}\text { Lining-up } \\
\text { toy cars }\end{array}$} & (1) & Gradual reduction in number of cars from 50 to 20 \\
\hline & (2) & Further reduction in length of lines to five cars only \\
\hline & (3) & Pairs of cars only allowed in the house, though these scattered in various rooms \\
\hline & (4) & Cars used in imaginative play \\
\hline \multirow{4}{*}{$\begin{array}{l}\text { Motor } \\
\text { mannerisms }\end{array}$} & (1) & 'Flapping' restricted at certain times of day (e.g. meal or TV times) \\
\hline & (2) & Increase in areas where flapping is restricted \\
\hline & (3) & Further restrictions to certain times only \\
\hline & (4) & Flapping allowed only in own room \\
\hline
\end{tabular}

Verbal

rituals

Resistance to environmental change
(1) Routines allowed only after period of non-ritual stereotyped conversation

(2) Number of repetitive sessions per day gradually reduced

(3) Number of repetitive questions per session reduced

(4) Routines allowed briefly at bedtimes only

(1) Minor change in angle of single chair

(2) Chair gradually moved away from usual position

(3) Other chairs moved to different angles

(4) Gradual changes in other household items (angles of doors, curtains etc.) 
ensure that the behaviour no longer intrudes in a distressing or unacceptable way into the life of the person with autism or that of his or her carers. Once an acceptable level of control is reached, obsessional behaviours or interests may have many beneficial effects. Not only can they be used as very powerful reinforcers, to increase participation in other, more productive activities (Howlin \& Rutter, 1987), but they can also be crucial in providing the autistic person with comfort, self-occupation or entertainment, which, because of their lack of other creative, social or imaginative skills, would be almost impossible to obtain otherwise. Longer-term outcome also can be positively affected by the way in which obsessions develop. Kanner, in his 1973 follow-up of young adults with autism, found that many of those who had made most progress had done so via obsessional interests (such as maths, music, general knowledge or scientific abilities) which, over time, developed into skills that were of social or occupational benefit.

\section{Improving social functioning}

The third main area of deficit in autism is social impairment. This affects almost every aspect of reciprocal social interaction, whatever the individual's level of functioning. For those who are least able, inappropriate social behaviours such as screaming, undressing or masturbating in public may be a major cause of disturbance. For those who are most able, the problems tend to be much more subtle, and include impairments in empathy, social understanding, or reciprocity and synchronisation (i.e. saying or doing things that in themselves are not unacceptable, but at the wrong time, in the wrong place or with the wrong person).

Somewhat paradoxically, the more obvious social problems are often easier to deal with, as long as firm rules are laid down from the child's earliest years about which behaviours are and are not acceptable. Dealing with more complex social deficits, however, presents much more of a challenge. Knowing how to make friends, how to be empathic, how to understand what others are feeling or thinking, are fundamental skills that we are born with, not ones acquired through teaching. Thus, interventions designed to overcome such basic deficits are almost certain to be of limited effectiveness. Nevertheless, there is some evidence that social skills groups specifically designed for children or adults with autism can improve certain aspects of social functioning (Mesibov, 1984; Williams, 1989).

Also, attempts have been made to improve social functioning by addressing deficits related to 'theory of mind'. The inability of individuals with autism to 'mind-read' or to understand other people's beliefs, ideas, thoughts or feelings has been well documented over recent years (see Baron-Cohen, 1995, for an excellent summary). Research has indicated that even after relatively brief intervention programmes employing a variety of different media, including computers, pictures, photographs, toys and actors, children with autism can be helped to understand beliefs and emotions (Ozonoff \& Miller, 1995; Hadwin et al, 1996; Swettenham, 1996). Unfortunately, generalisation to other, untrained areas tends to remain limited. Teaching approaches of this kind are still in their infancy, and it is hardly to be expected that relatively brief training programmes could have a widespread impact on such a fundamental deficit. Nevertheless, the systematic introduction of strategies specifically designed to increase the ability to 'mind-read' into educational programmes could have a much wider impact, and is worthy of greater exploration (Howlin et al, 1997).

\section{The need for early diagnosis and understanding of autism}

Despite a growing consensus that autism almost always has a prenatal onset (Volkmar et al, 1985) diagnosis before the age of three years is still rare (Baron-Cohen et al, 1996). Indeed, in a recent largescale survey in the UK, the average age of diagnosis was 6.1 years (Howlin \& Moore, 1997). Delays in diagnosis have important implications, since appropriate advice to parents and the establishment of effective management strategies in the earliest years can have a major impact on subsequent development. In particular, attention to a few basic rules, can help to minimise or avoid the development of more serious problems later.

First, professional help to develop simple but effective communication strategies (for both children and parents) must be sought from as early an age as possible. This will almost certainly help to reduce the growth of disruptive behaviours, which may otherwise become the child's principal means of communication.

Second, behaviours that will be unacceptable in later life must not be allowed or encouraged in young children. Many behaviours that are tolerated in childhood may be viewed as challenging or disruptive in adults, not because the intensity or frequency of the behaviours have increased, but because other people's attitudes have changed. A young boy who loves to stroke people's hair is unlikely to meet with disapproval, but the same behaviour in a 30-year-old man will produce a very different response. Behaviours may also become unacceptable as individuals become 
more skilled or determined at carrying them out. For example, one child's obsession with washing machines provided his mother with much needed respite when he was young. However, by the time he was a large, active teenager he was able to break into other houses to indulge his obsession, so that a previously innocent behaviour became a threat both to himself and to others.

Third, routines and obsessional behaviours must never be allowed to reach a level at which they dominate the life of either the child or those caring for him. Often, bewildered parents will, understandably, give in to apparently innocuous routines, such as turning left out of the house rather than right, in order to avoid the distress this causes to their child. Over the years, however, such routines can become more and more entrenched, so that the same parents may eventually have to make elaborate detours whenever they go out, in order to satisfy the child's demands.

Without help, parents are unlikely to be able to identify potential problems in early childhood, and will naturally tend to accept these, perhaps with disastrous results in the future. It is up to professionals who are knowledgeable about autism, and the behaviours that are likely to prove troublesome in later life, to advise, to warn, and to develop appropriate strategies for families, schools and others to follow.

\section{Summary and conclusions}

There are no easy answers to the problems of autism but recognition of the impact that communication and social deficits and obsessional behaviours have on overall functioning can be important in minimising the devastation that this disorder can bring. Appropriate advice and professional support for families to enable them to deal effectively with problems from an early age can do much to reduce the severity of later difficulties, and to prevent the unnecessary development of secondary behavioural problems. The focus of treatment should not be on 'cures' or 'miracles', which will inevitably raise false hopes, but on the provision of appropriate educational and therapeutic facilities, which will ultimately prove far more effective in improving the quality of life for all concerned.

\section{References}

Baron-Cohen, S. (1995) Mindblindness: An Essay on Autism and Theory of Mind. Cambridge, MA: MIT Press.
-, Cox, A., Baird, G., et al (1996) Psychological markers in the detection of autism in infancy in a large population. British Journal of Psychiatry, 168, 158-163.

Biklen, D. (1993) Communication Unbound: How Facilitated Communication is Challenging Traditional Views of Autism and Ability/Disability. New York: Teachers College Press.

Campbell, M. \& Cueva, J. E. (1995) Psychopharmacology in child and adolescent psychiatry: a review of the past seven years. Part II. Journal of the American Academy of Child E Adolescent Psychiatry, 34, 1262-1272.

-, Schopler, E., Cueva, J. E., et al (1996) Treatment of autistic disorder. Journal of the American Academy of Child \& Adolescent Psychiatry, 35, 134-143.

Coleman, M. (1992) Pharmacological therapies. In Diagnosis and Treatment of Autism (ed. C. Gillberg), pp. 257-270. New York: Plenum Press.

Durand, B. M. (1990) Severe Behavior Problems: A Functional Communication Approach. New York: Guilford Press.

— \& Carr, E. G. (1991) Functional communication training to reduce challenging behaviour: maintenance and application in new settings. Journal of Applied Behavior Analysis, 24, 251-254.

Emerson, E. (1995) Challenging Behaviour: Analysis and Intervention. Cambridge: Cambridge University Press.

Gould, G. A., Rigg, M. \& Bignell, L. (1991) The Higashi Experience: The report of a Visit to the Boston Higashi School. London: National Autistic Society.

Grandin, T. \& Scariano, M. (1986) Emergence Labelled Autistic. Tunbridge Wells: Costello.

Green, G. (1994) The quality of the evidence. In Facilitated Communication: The Clinical and Social Phenomenon (ed. H. C. Shane), pp. 156-226. San Diego, CA: Singular Press.

Hadwin, J., Baron-Cohen, S., Howlin, P., et al (1996) Can a theory of mind be taught to children with autism? Development $\mathcal{E}$ Psychopathology, 8, 345-365.

Howlin, P. (1989) Changing approaches to communication training with autistic children. British Journal of Disorders of Communication, 24, 151-168.

— \& Rutter, M. (1987) Treatment of Autistic Children. Chichester: Wiley.

- \& Moore, A. (1997) Diagnosis in autism: a survey of over 1200 parents. Autism: International Journal of Research and Practice, in press.

—- Baron-Cohen, S., Hadwin, J., et al (1997) Teaching Children with Autism to Mindread. A Practical Manual for Parents and Teachers. Chichester: Wiley.

Irlen, H. (1995) Viewing the world through rose tinted glasses. Communication, 29, 8-9.

Jolliffe, T., Landsdown, R. \& Robinson, T. (1992) Autism: A Personal Account. London: National Autistic Society.

Jordan, R. \& Powell, S. (1995) Understanding and Teaching Children with Autism. Chichester: Wiley.

Kanner, L. (1943) Autistic disturbances of affective contact. Neroous Child, 2, 217-250.

- (1973) Childhood Psychosis: Initial Studies and New Insights. New York: Winston/Wiley.

Kaufman, B. (1981) A Miracle to Believe In. New York: Doubleday.

Layton, T. L. \& Watson, L. R. (1995) Enhancing communication in non-verbal children with autism. In Teaching Children with Autism: Strategies to Enhance Communication and Socialization (ed. K. A. Quill), pp. 73-104. New York: Delmar.

Lewis, M. H. (1996) Psychopharmacology of autism spectrum disorders. Journal of Autism and Developmental Disorders, 26, 231-236.

Lord, C. \& Rutter, M. (1994) Autism and pervasive developmental disorders. In Child and Adolescent Psychiatry: Modern Approaches (3rd edn) (eds M. Rutter, E. Taylor \& L. Hersov), pp. 569-593. Oxford: Blackwell.

McEachin, J. J., Smith, T. \& Lovaas, O. I. (1993) Long-term outcome for children with autism who received early intensive behavioral treatment. American Journal of Mental Retardation, 97, 359-372.

Mesibov, G. B. (1984) Social skills training with verbal autistic adolescents and adults: a program model. Journal of Autism and Developmental Disorders, 14, 395-404.

Ozonoff, S. \& Miller, J. (1995) Teaching theory of mind: a new approach to social skills training for individuals with autism. Journal of Autism and Developmental Disorders, 25, 415-434. 
Perry, R., Cohen, I. \& DeCarlo, R. (1995) Case study: deterioration, autism and recovery in two siblings. Journal of the American Academy of Child \& Adolescent Psychiatry, 34, 233-237.

Quill, K. A. (1995) Teaching Children with Autism: Strategies to Enhance Communication and Socialization. New York: Delmar.

Richer, J. \& Zappella, M. (1989) Changing social behaviour: the place of holding. Communication, 23, 35-39.

Rimland, B. (1994a) Information pack on drug treatments for autism. Autism Research Review International. Information Pack P6. San Diego, CA: Autism Research Institute.

-- (1994b) Information pack on vitamins, allergies and nutritional treatments for autism. Autism Research Review International, Information Pack P24. San Diego, CA: Autism Research Institute.

Ritvo, E. R., Freeman, B. J., Yuwiler, A., et al (1986) Fenfluramine treatment of autism: UCLA collaborative study of 81 patients at nine medical centres. Psychopharmacology Bulletin, 22, 133140.

Rydell, P. J. \& Prizant, B. M. (1995) Assessment and intervention for children who use echolalia. In Teaching Children with Autism: Strategies to Enhance Communication and Socialization (ed. K. A. Quill), pp. 105-132. New York: Delmar.

Schuler, A. L., Peck, C. A., Willard, C., et al (1989) Assessment of communicative means and functions through interview: assessing the communicative capabilities of individuals with limited language. Seminars in Speech and Language, 10, 51-61.

Stehli, A. (1992) The Sound of a Miracle: A Child's Triumph over Autism. London: Fourth Estate.

Swettenham, J. (1996) Can children with autism be taught to understand false beliefs using computers? Journal of Child Psychology and Psychiatry, 36, 157-166.

Volkmar, F., Stier, D. \& Cohen, D. (1985) Age of recognition of pervasive developmental disorders. American Journal of Psychiatry, 142, 1450-1452.

Welch, M. (1988) Holding Time. London: Century Hutchinson.

Williams, D. (1992) Nobody Nowhere. London: Corgi.

- (1994) Somebody Somewhere. London: Corgi.

Williams, T. I. (1989) A social skills group for autistic children. Journal of Autism and Developmental Disorders, 19, 143-156.

Wing, L. (1993) The definition and prevalence of autism: a review. European Journal of Child \& Adolescent Psychiatry, 2, 61-74.

- (1996) Autistic spectrum disorders. British Medical Journal, $312,327-328$.

\section{Multiple choice questions}

1. The most effective intervention strategies for autism involve:

a pharmacological treatments

b family therapy

c facilitated communication

d behavioural programmes.
2. Autism is:
a a disorder of childhood
b a developmental disorder that lasts throughout life
c an emotional disorder
d another term for 'learning disability'.

3. Individuals with autism:
a are always highly intelligent
b are always severely cognitively impaired
c have a widely varying range of abilities
d always have exceptional skills in certain areas.

4. Behavioural problems in autism:
a are frequently associated with social/ communication deficits or obsessional tendencies
b are due to inadequate parental handling
c can be markedly reduced by medication
$\mathrm{d}$ are impossible to control.

5. Very intensive behavioural interventions:
a are likely to result in children being cured
b have unknown long-term effects
c are always highly effective
d result in major stress for families.

\begin{tabular}{|cccccccccc|}
\hline \multicolumn{1}{|c}{ MCQ } & answers & & & & & & \\
1 & 2 & & 3 & & 4 & & 5 & \\
a & F & a & F & a & F & a & T & a & F \\
b & F & b & T & b & F & b & F & b & T \\
c & F & c & F & c & T & c & F & c & F \\
d & T & d & F & d & F & d & F & d & F \\
\hline
\end{tabular}

